\title{
A mulher na vida pública: um mapa das moralidades no Facebook ${ }^{1}$

\author{
Danila Cal, Regiane Lucas Garcêz, \\ Janine de Kássia Rocha Bargas e Thais dos Santos Choucair
}

\section{Resumo}

0 artigo investiga entendimentos morais sobre a participação da mulher na vida pública a partir de comentários dos posts no Facebook sobre as matérias As explosões nervosas da presidente, da IstoÉ, e Bela, recatada e do lar, da Veja. Traçamos um mapa das moralidades sobre atividade profissional, temperamento e relações sociais, que aponta como consensos tácitos: a visão positiva da mulher discreta e responsável pelo lar e a visão negativa da mulher afeita às emoções. Desafia essas concepções: a ideia de mulher forte e que pode escolher a vida profissional. Identificamos que moralidades tidas como ofensivas podem criar identificação e afinidades a fim de instaurar novas gramáticas morais.

\section{Palavras-Chave}

Mulher. Moralidades. Facebook.

Danila Cal I danilagentilcal23@gmail.com Doutora em Comunicação Social pela Universidade Federal de Minas Gerais - UFMG, Brasil. Professora do Programa de Pós-Graduação em Comunicação, Cultura e Amazônia da Universidade Federal do Pará - UFPA.

Regiane Lucas Garcêz | regiane.lucas@gmail.com Professora Adjunta do Departamento de Comunicação Social da UFMG, doutora, mestre e jornalista pela mesma universidade.

\section{Janine de Kássia Rocha Bargas । \\ ninebargas@gmail.com}

Doutoranda em Comunicação Social pela UFMG. Bolsista Capes. Integrante dos Grupos de Pesquisa Mídia e Esfera Pública (UFMG) e Comunicação, Política e Amazônia (UFPA).

Thais dos Santos Choucair / choucair.thais@gmail.com Doutoranda em Comunicação Social pela UFMG. Bolsista Fapemig. Participa do Grupo de Pesquisa Mídia e Esfera Pública (UFMG)

\section{Introdução}

A presença cada vez maior das mulheres na política formal - embora ainda tímida e desproporcional em relação aos homens - vem revelando determinados consensos morais sobre como deve ser essa mulher, se de fato ela deve atuar na política, quais atribuições e qualidades ela deve ter. 0 pano de fundo moral acionado para expressar esses entendimentos revela consensos compartilhados intersubjetivamente, sedimentados historicamente e atualizados na relação entre indivíduos (TAYLOR, 1997).

Neste trabalho, analisamos os consensos tácitos acerca da mulher na vida pública desvelados nas conversações informais no Facebook desencadeadas por materiais dos media. Partimos do contexto de polarização e acirramento de ideias e valores em dois casos da imprensa brasileira ocorridos em 2016: um envolvendo a então presidenta Dilma Rousseff e outro, Marcela Temer, esposa do então vicepresidente Michel Temer. 
No primeiro caso, a capa da Revista Isto É, da primeira semana de abril de 2016, traz a imagem de Dilma Rousseff com o semblante enraivecido e a manchete: "As explosões nervosas da presidente". A capa menciona ainda "surtos de descontrole", quebra de móveis no Palácio do Planalto e xingamento de autoridades. Conclui: "[...] e [Dilma] perde (também) as condições emocionais de conduzir o país". A matéria traz uma foto de Dilma de costas,andando com as mãos levantadas e 0 título "Uma presidente fora de si"(PARDELLAS; BERGAMASC0, 2016, s/p). A matéria conta que Dilma estaria fazendo uso de medicamentos calmantes, relacionando-os aos fatos políticos que levaram ao seu afastamento do cargo; apresenta relatos de vários momentos de "fúria"; dados sobre transtornos mentais e comparações entre a situação mental atribuída à Dilma; e casos históricos de outras chefes de Estado consideradas loucas. 0 post na fanpage da IstoÉ apresentava a legenda "Fora de si, a presidente quebra móveis no Palácio, grita com subordinados, xinga autoridades e ataca poderes constituídos" e, abaixo da imagem, o seguinte texto: "Diante da iminência da queda, Dilma tem surtos de descontrole emocional".

No segundo caso, duas semanas depois, a Revista Veja publicou uma reportagem sobre Marcela Temer, esposa do então vice-presidente Michel
Temer, com 0 título "Bela, recatada e ‘do lar'”2. 0 subtítulo dizia: "Quase primeira-dama, 43 anos mais jovem que o marido, aparece pouco, gosta de vestidos na altura dos joelhos e sonha em ter mais um filho com o vice" (LINHARES, 2016, s/p). 0 texto aborda aspectos do relacionamento de Marcela com Temer (como se conheceram, período de namoro, casamento, informações do filho do casal, dentre outros); a formação universitária dela - deixada de lado para se tornar uma mulher "do lar" - e os seus cuidados com a beleza. Entre as fontes ouvidas, estão a tia e 0 cabeleireiro de Marcela, e amigos do então vice-presidente. Marcela não aparece como fonte em nenhuma citação direta da reportagem. 0 texto é concluído com a frase: "Michel Temer é um homem de sorte".

Em trabalho anterior (GARCÊZ e CAL, 2013), discutimos de que forma expressões de desrespeito ou preconceito veiculadas nos media desvelam questões pouco tematizadas na esfera pública, descortinando consensos tácitos e incentivando o debate público acerca de valores sociais com vistas à ampliação de gramáticas morais (HONNETH, 2003). No presente artigo, consideramos que a repercussão das expressões de desrespeito pode tanto cristalizar e reforçar ideias e valores conservadores sobre a mulher na política, bem como desafiá-los. Para identificar a conformação desses valores, traçamos um 
mapa das moralidades acerca da participação das mulheres na vida pública particularmente no que se refere: à a) atividade profissional, ao b) temperamento e às c) relações sociais.

0 corpus do nosso trabalho é constituído por todos os comentários nos posts dessas duas matérias no Facebook, publicadas nas páginas da Isto É e da Veja, nas suas datas de publicação (01 abr. 2016 e 18 abr. 2016, respectivamente) com 0 intuito de captar a repercussão imediata dos conteúdos ${ }^{3}$. Nosso mapa de moralidades configurou-se a partir a) da análise de conteúdo para codificar os principais significantes textuais que, agrupados, revelam sentidos e padrões relacionados aos valores e ideias acerca das mulheres na vida pública; e b) de uma análise qualitativa em relação aos posts mais comentados, capaz de identificar a complexidade dessas moralidades.

0 artigo está dividido em cinco seções. Na primeira, fazemos uma discussão acerca do lugar dos media - tradicionais e novos - na constituição de uma topografia moral das relações sociais. Na segunda, discutimos nossa compreensão sobre a categoria "mulher na vida pública”. Em seguida, apresentamos a metodologia. Na quarta seção descrevemos os resultados e, na quinta, por fim, apresentamos 0 mapeamento das moralidades.

\section{Media e moralidades}

0 modo como se conformam os sentidos acerca da mulher na vida pública, suas funções, formas de atuação e comportamentos desejáveis é norteado por aquilo que chamamos de pano de fundo moral. Essas definições são materializações de valores e moralidades previamente constituídos e historicamente sedimentados na vida social. Interessa-nos aqui discutir como, a partir de material dos media, elementos centrais da configuração de uma topografia moral das relações sociais (TAYLOR, 1997) são reverberados em conversações informais. São eles: a linguagem, as interações sociais, a visibilidade e a possibilidade da transformação de novos horizontes éticos e morais.

Na obra de Charles Taylor (1995; 1997)4, é central a reconstrução desse pano de fundo moral que serve de guia para as nossas ações cotidianas. Esses sentidos são quase sempre implícitos, expressando-se na maioria das vezes em práticas sociais ou instituições, em vez de estarem presentes em doutrinas explícitas (SOUZA, 2000).

A coleta dos comentários e respostas aos comentários de cada post foi realizada no dia 2 de abril de 2017, momento de definição da feitura da pesquisa. Utilizamos o software Facepager para fazer a coleta.

Taylor parte de uma perspectiva de ciência que defende o holismo metodológico, uma forma de compreender os fenômenos sociais não de modo isolado, mas a partir de um pano de fundo social e cultural onde os sujeitos estão inseridos (TAYLOR, 1995, 1997). A partir de uma inspiração hegeliana, 0 autor dá ênfase às inclinações práticas intersubjetivas para além das ordenações estatais ou das convicções individuais. 
0 que constitui esse pano de fundo moral não está na ordem dos desejos ou intenções, mas se relaciona a um mundo de "sentimentos morais" que existe independentemente de nosso desejo ou consciência. A esse pano de fundo moral mais profundo só temos acesso através da reflexão e da autorreflexão.

Os sujeitos são capazes de promover distinções e fazer avaliações daquilo que é bom ou ruim, que tem mais ou menos valor. É o que Taylor (1995) chama de avaliações fortes. A habilidade humana de refletir sobre as concepções de bem e hierarquizálas é ancorada tanto na biografia individual dos sujeitos, quanto na tradição cultural e linguística na qual o sujeito está inserido.

Conforma-se uma hierarquia de valores que se desdobra e se objetifica a partir dessas moralidades que define o que é importante, válido, digno de vergonha ou de admiração. Ainda que implícitos, esses valores ganham corpo por meio da linguagem.

Valores são entidades objetivas e não subjetivas. Eles encontram-se objetivados tanto na língua como em práticas sociais e instituições e é a forma peculiar na qual 0 sujeito se vincula e reflete sobre esses valores objetivados que constitui sua identidade peculiar. (SOUZA, 2000, p. 100)

Desse modo, as moralidades vão sendo sedimentadas a partir da materialização linguageira do pano de fundo moral, que nomeia, cria sentidos, faz circular ideias e práticas sociais e que, para os nossos interesses neste artigo, configura a imagem daquilo que deveria ser a mulher pública na política. As interações sociais fundadas intersubjetivamente e sempre engendradas pela linguagem vão não apenas configurando uma hierarquia de valores, como também constituindo identidades, visões de mundo e potencializando transformações morais e sociais.

As interações sociais são, desse modo, constituintes das realidades sociais e dessas moralidades na medida em que promovem uma dinâmica relacional que vincula os sujeitos ao mundo social. 0 compartilhamento intersubjetivo é aquilo que promove a mediação entre as compreensões individuais, a socialização de valores e a sedimentação das moralidades que conduzem as práticas dos sujeitos. Tais interações, entretanto, também são capazes de potencializar novos valores e novas hierarquias morais. Ao se tornarem visíveis, determinados entendimentos de mundo alçam a possibilidade de serem contestados e promoverem transformação social e novos padrões de justiça. Por meio das interações sociais, há um desvelamento de questões antes invisibilizadas, ligadas à opressão e à desigualdade social, que dizem respeito aos padrões de justiça de uma sociedade. Na arena pública, é possível desvelar elementos morais e questões simbólicas muitas vezes considerados injustos. É o que Taylor (1995) e Markell (2003) chamam de disclosure, uma concepção heideggeriana de tornar presente, dar existência. 
Desse modo, as transformações sociais, a alteração dos padrões de injustiça e a reconfiguração das hierarquias de valores prescindem de uma visibilidade dessas moralidades sedimentadas para que elas possam ser desafiadas. Há um potencial reflexivo naquilo que se torna visível (TAYLOR, 1995) capaz de propor novas gramáticas morais (HONNETH, 2003), instaurar o novo (ARENDT, 1992; MARKELL, 2003) e questionar relações de poder (MCNAY, 2008; CAL, 2016). Não apenas a visibilidade, mas a possibilidade de "um conflito moral entre 0 sujeito e seu ambiente social" (HONNETH, 2003, p. 141) reverbera nas relações sociais de forma a mobilizar sujeitos que se subjugam às mesmas fontes de opressão.

Nesse cenário, consideramos as possibilidades, tensões e funções que os media podem exercer em relação às transformações sociais como um lugar de reprodução de valores, ao mesmo tempo em que podem possibilitar 0 alargamento das relações de reconhecimento (MAIA, 2012). Como afirma Gomes (2008), os media constituem a esfera de visibilidade pública e tornam disponível "uma espécie de quadro do mundo" (GOMES, 2008, p. 143).

Os media - tradicionais ou novos - correspondem ao principal palco dessa esfera de visibilidade, além de permitirem a passagem da estrutura espacial das interações simples para a generalização da esfera pública (HABERMAS, 2003). Possibilitam ainda uma ampla visibilidade e fomentam as interações sociais das mais diversas naturezas, incluindo aquelas que acontecem nas redes sociais online e nas microinterações mediadas. Contribuem sobremaneira para a sedimentação do horizonte das normas morais, tácito e implícito no cotidiano social. Reproduzem rótulos, desvalorização de certos modos de vida, ofensas e moralidades que cercam a configuração da imagem da mulher na vida pública. Por outro lado, também auxiliam na reestruturação dessas normas e podem ser locus de novas gramáticas, pois alimentam debates públicos e concedem espaço para a reflexividade e para novas definições daquilo que é bom e tem valor, inclusive acerca aquilo que se considera importante sobre as mulheres na política.

\section{A categoria Mulheres na vida pública: de quem estamos falando?}

Um conjunto de percepções morais acerca da divisão sexual do trabalho considera as mulheres responsáveis pelo espaço doméstico e pela reprodução, e os homens pelas atividades econômicas e políticas (ARENDT, 1992; OKIN, 2008). "As mulheres têm sido vistas como 'naturalmente' inadequadas à esfera pública, dependentes dos homens e subordinadas à família" (OKIN, 2008, p. 308).

Face a esse pano de fundo moral que destina a mulher ao cuidado e à esfera privada, opõese 0 entendimento de que as mulheres devem não apenas ocupar outros postos de trabalho 
como também os espaços formais de decisão política. "Ausentes das esferas de decisão, as mulheres, enquanto grupo, estão em uma situação desprivilegiada para fazer ver suas experiências e transformar seus interesses em questões políticas legítimas e prioritárias". (MOTA; BIROLI, 2014, p. 200). Há, portanto, um descompasso entre as mulheres como maioria, inclusive populacional (de acordo com o Censo 2010 do IBGE correspondem a 51\% da população), e os modos simbólicos, políticos e sociais pelos quais são posicionadas na cena pública.

A própria definição do termo "mulher"e das marcações identitárias que o cercam, compõe um conjunto de moralidades sedimentadas que compreende essa categoria como homogênea e plenamente identificável pela distinção biológica. A marcação da categoria "mulher"foi determinante, como identidade política, para gerar solidariedade entre grupos e lançar luz sobre os modos de opressão e dominação vivenciadas por mulheres. Não revela, entretanto, a heterogeneidade interna ao grupo e acaba por reproduzir padrões de opressão e subalternização em relação às diferenças internas (BUTLER, 1998; 2003; SARDENBERG, 2007; MATOS, 2008; BIROLI, 2014; MIGUEL, 2014).

Para algumas autoras feministas, falar em gênero seria um modo mais abrangente de abordar a questão e destacar os componentes culturais que participam dos processos de identificação de mulheres. Em vez de partir de características biológicas e de distinções daquilo que seria próprio do homem ou da mulher, a compreensão de gênero deve remeter a processos sociais, históricos e culturais que atuam na definição do que seria masculino ou feminin $0^{5}$, mantendo ainda o terreno aberto à construção de outros gêneros (MATOS, 2008; SARDENBERG, 2007).

Luís Felipe Miguel (2014) argumenta que a desconstrução de gênero e a sua desvinculação de sexo afasta o feminismo da sua ação concreta. "Nós vivemos um sistema binário de gêneros, historicamente construído, reproduzido de forma cotidiana pelas práticas sociais hegemônicas, nas quais cada gênero está intimamente associado a um sexo biológico" (MIGUEL, 2014, p. 81). Gênero seria assim um "desdobramento necessário das diferenças sexuais" (MIGUEL, 2014, p. 81, grifo do autor).

Frente a esse cenário de tensões e questionamento, como trabalhar neste estudo com as categorias "mulher" e "gênero"? Em nosso trabalho, interessa compreender uma categoria "mulher" que contemple as diferenças internas e que seja capaz de indicar, como aponta Chantal Mouffe, "como se transforma a diferença sexual em uma distinção pertinente dentro das como sempre relativo; produzido por meios complexos, isto é, por amplos e complexos quadros epistêmicos e referindose não apenas às ideias, mas também às instituições e estruturas, práticas cotidianas, rituais; enfim, tudo aquilo que constituiria as relações sociais". 
relações sociais. Como se constroem relações de subordinação através desta distinção?" (MOUFFE, 1992, p. 373). 0 desafio é manter uma perspectiva crítica e atenta para que não se incorra no aprisionamento das mulheres a definições apriorísticas e essencializadoras. Nesse sentido, consideramos, num plano geral, a noção de gênero como elemento que diz das relações de poder envolvidas na constituição social, comunicacional e histórica do que seria o feminino ou o relativo a mulheres. Num plano mais específico, buscamos examinar como a própria categoria "mulher" é construída de modo situado dos comentários sobre as reportagens aqui analisados.

\section{Metodologia}

Compartilhamos da perspectiva de França (2006) sobre a análise comunicacional que trata "do movimento de textos (narrativas, discursos, representações) no contexto das interlocuções. É nesse movimento que os sujeitos (agentes e pacientes do processo comunicativo) ganham existência - e é onde podem ser apanhados" (FRANÇA, 2006, p. 86).

Para compreendermos a hierarquia valorativa sobre mulheres na vida pública, que alimenta as conversações informais relacionadas às matérias da IstoÉ e da Veja, postadas no Facebook, buscamos desenvolver um mapa das moralidades. Não analisamos as reportagens comparativamente - trabalho já realizado por Ana Maria Veloso et al (2017) - mas as conversações que emergem das matérias.

Recorremos a procedimentos metodológicos que consideram a conjugação de aspectos quantitativos e qualitativos. Primeiro foi realizada uma análise de conteúdo definida, por Kolbe e Burnett (1991, p. 243), "como um método de pesquisa de observação usado para avaliar sistematicamente o conteúdo simbólico de todas as formas de comunicações registradas". 0 objetivo é reduzir as muitas palavras de um texto a um conjunto reduzido de categorias de conteúdo (BARDIN, 1995). Utilizamos, assim, a análise de conteúdo para codificar os principais significantes textuais que, agrupados, revelam sentidos e padrões que consideram a complexidade da construção de valores e ideias acerca das mulheres na vida pública. Num segundo momento, a partir das categorias da análise de conteúdo, realizamos uma análise qualitativa dos comentários, capaz de revelar as moralidades sedimentadas e as concepções que desafiam essas moralidades.

\section{Corpus}

Nosso corpus inicial foi composto pelo conjunto dos comentários feitos nas postagens das fanpages das revistas no Facebook, tanto da capa da IstoÉ com Dilma, quanto da matéria de Veja sobre Marcela Temer. Ao todo foram 7.378 comentários, sendo 4.963 relacionados ao post da IstoÉ e 2.415, ao post da Veja, o que corresponde a todos os comentários a essas postagens até a data final de coleta, 02 de abril de 2017. 
Para definirmos o corpus que seria

analisado, realizamos uma primeira

codificação, identificando as postagens por

relevância(relevante ou irrelevante) e por

tópico(dentro ou fora do assunto estudado) ${ }^{6}$.

Foram considerados relevantes aqueles

comentários que apresentaram alguma relação

com a temática da matéria. Os irrelevantes foram

aqueles que expressavam apenas interjeições,

expressões incompletas ou sem sentido definido,

marcações de usuários do Facebook. Por

exemplo: "kkkk...", “meu deus", "nossa!". Já o

tópico indicou se 0 comentário analisado estava

dentro do assunto deste estudo, fazendo ou não

referência direta ou indireta às mulheres de forma

geral, a Marcela Temer ou a Dilma Rousseff. Foram

identificados como fora do tópico os comentários

que tratavam de política sem fazer menção,

explícita ou implícita, ao tema das mulheres na

vida pública. São exemplos assuntos como a

operação Lava Jato ou expressões genéricas como

"não vai ter golpe".

Nessa primeira codificação, utilizamos como amostra $10 \%$ de todos os comentários feitos no dia da publicação das matérias nas páginas dos dois veículos para verificar a confiabilidade das categorias. 0 teste de confiabilidade foi feito por meio de dois índices: a porcentagem de concordância e o Kappa ${ }^{7}$. Chegamos a 98,34\% de concordância e Kappa 0.784 na categoria

relevância, e $98.5 \%$ de concordância e índice Kappa 0.781 na categoria tópico. As duas categorias mostraram-se, assim, confiáveis e consensuadas entre as duas codificadoras.

Após essa primeira codificação, verificamos que os comentários relevantes e dentro do tópico tinham a seguinte proporção para Veja e para IstoÉ: 40\% para primeira, o que corresponde proporcionalmente a 1.161 comentários considerando 0 total de respostas ao post; e $25 \%$ na segunda, o que corresponde a 1.230 comentários ao post na IstoÉ no período analisado.

Esses totais de comentários (1.161 e 1.230) compuseram 0 universo da pesquisa e serviram de base para seleção da amostra para análise e codificação final, com todas as categorias. Nessa segunda fase de codificação fizemos um teste de confiabilidade com $10 \%$ do universo total de posts, totalizando 239 comentários (116 na página da Veja e 123 na da IstoÉ). Para garantir uma amostra aleatória, sorteamos as páginas ${ }^{8}$ dos comentários a serem codificados. Para garantir que 0 teste abrangesse todo o material, selecionamos três momentos diferentes: comentários no início, no meio e no fim dia. 0s índices Kappa se mostraram suficientes e os resultados demonstraram a confiabilidade das categorias ${ }^{9}$. 
0 passo seguinte foi a codificação do corpus

a partir de uma amostra de $95 \%$ de nível de confiança e 5\% de erro amostral. Para os 1.161 comentários da Veja, a amostra foi de 284. Para os 1.230 comentários da IstoÉ, a amostra foi de 313. Foram codificados, então, para a análise, 597 comentários.

\section{Categorias de análise}

Nossas categorias de análise foram definidas com base nas discussões teóricas e no exame prévio dos posts que gerou um livro de códigos. A codificação foi dividida num nível mais descritivo - identificando 0 sex $0^{10}$ do autor do comentário e se a postagem concordava ou não com a matéria -; e num nível mais analítico - considerando

a) atividade profissional, b) temperamento e c) relações sociais, quando relacionados às mulheres de modo geral ou à Dilma e à Marcela.

0 sexo foi identificado a partir do nome e das imagens do perfil. Já a concordância ou discordância foram identificadas em relação à abordagem ou ao conteúdo das matérias. $\mathrm{Na}$ categoria "concorda", incluímos todos os posts que endossam ou reforçam as matérias, explícita ou implicitamente. A categoria "discorda" foi subdividida em outras seis: "Sem explicar o porquê" ("revista ridícula", "que matéria é essa?!" etc.), "Falta de credibilidade" ("Cadê a fonte?", "como vocês sabem isso?" etc.), "Falta de seriedade" ("Tá mais para Tititi", "isso é revista de fofoca agora?" etc.), "Aponta machismo" ("só porque ela é mulher", "isso é sexismo" etc.) e "Discorda por outros motivos" (motivo não listado).

No nível mais analítico, elencamos categorias referentes à atividade profissional, ao temperamento e às relações sociais, tanto em relação às mulheres em geral quanto a Dilma e Marcela. Partimos, num duplomovimento, tanto da literatura que nos informa sobre as competências morais (HABERMAS, 1979) ou às "obrigações intersubjetivas" (MENDONÇA, 2007) valorizadas socialmente, como dos próprios aspectos destacados pelas revistas acerca das mulheres. Em atividade

A coleta dos comentários, por meio do software FacePager, gerou páginas em formato PDF.

Para essa segunda fase de codificação fizemos um teste de confiabilidade com $10 \%$ do universo total de posts, totalizando 239 comentários (116 na página da Veja e 123 na da IstoÉ). Para garantir uma amostra aleatória sorteamos as páginas do PDF dos comentários a serem codificadas. Já para garantir que o teste abrangesse todo o material, codificamos três momentos diferentes: comentários no início, no meio e no fim dia. Os índices Kappa mostraram-se suficientes. Na categoria sexo, o Kappa foi de 0.9864 para mulher e 0.9842 para homem. Na categoria Concordância, o Kappa foi de 0.85 para concorda e variou entre 0.6031 e 0.6976 nos tipos de discorda. Nesse caso, o tipo discorda sem explicar os motivos obteve $0.4992,0$ que é considerado "moderado". Na categoria Atividade Profissional, os índices variaram entre 0.500 e 0.8632 . Na categoria Temperamento, os índices variaram entre 0.5802 e 0.8762 . Na categoria Relações Sociais, os índices variaram entre 0.6495 e 1.0. 0s resultados demonstraram a confiabilidade das categorias.

10 Apesar dos questionamentos ao binarismo de sexo, trata-se de uma identificação preliminar relevante para esta pesquisa já que, nesse momento, precisávamos levantar elementos morais predominantes mobilizados ou questionados por essas categorias sociais hegemônicas ligadas ao sexo biológico (MIGUEL, 2014). 
profissional investigamos a construção

de valores acerca do exercício do trabalho

de mulheres. A categoria temperamento

refere-se a algum aspecto da personalidade ou do comportamento. Já na categoria

relações sociais, referimo-nos à

valorização ou desvalorização de como a

mulher se localiza e age em relação a um

conjunto mais amplo de "outros".
Em cada categoria, avaliamos se 0 autor do

post apresentava elementos que valorizavam

ou desvalorizavam as mulheres de modo

geral, Dilma Rousseff ou Marcela Temer de

modo específico. Para cada categoria, havia

as opções "não aborda", quando não era

mencionada explicitamente no post, e "não foi

possível identificar". Elegemos os seguintes

códigos (Quadro 1):

Quadro 1: Categorias e subcategorias de análise

\begin{tabular}{|c|c|c|c|}
\hline & Atividade profissional & Temperamento & Relações Sociais \\
\hline Valoriza & $\begin{array}{l}\text { Atuação em casa; } \\
\text { Atuação na política; } \\
\text { Atuação em atividades } \\
\text { relativas à beleza/corpo } \\
\text { Atividades de estudo/instrução } \\
\text { formal; } \\
\text { Atuando onde deseja (questão } \\
\text { de escolha). }\end{array}$ & $\begin{array}{l}\text { Sensata; } \\
\text { Equilibrada; } \\
\text { Forte; } \\
\text { Simples; } \\
\text { Fina/sofisticada; } \\
\text { Carinhosa; } \\
\text { Delicada; } \\
\text { Comportada/Recatada; } \\
\text { Feminina }\end{array}$ & $\begin{array}{l}\text { Discreta; } \\
\text { Obediente à família; } \\
\text { Autônoma; } \\
\text { Feminista; } \\
\text { Decente/Recatada; } \\
\text { De esquerda; } \\
\text { De direita; } \\
\text { Batalhadora; } \\
\text { Amiga/companheira; } \\
\text { Empoderada; } \\
\text { Que é mãe }\end{array}$ \\
\hline Desvaloriza & $\begin{array}{l}\text { Atuação em casa; } \\
\text { Atuação em prostituição; } \\
\text { Atuação na política; } \\
\text { Atividade de estudo/instrução } \\
\text { formal; } \\
\text { Mulher corrupta; } \\
\text { Mulher incompetente; } \\
\text { Critica ausência de mulheres } \\
\text { na política; }\end{array}$ & $\begin{array}{l}\text { Histérica; } \\
\text { Megera/Má; } \\
\text { Mandona; } \\
\text { Masculinizada; } \\
\text { Fraca; } \\
\text { Exibida; } \\
\text { Sofrida; } \\
\text { Que se faz de vítima; } \\
\text { Louca/descontrolada; } \\
\text { Arrogante }\end{array}$ & $\begin{array}{l}\text { Que emite opiniões; } \\
\text { Voltada para a família/lar; } \\
\text { Feminista; } \\
\text { Consumista; } \\
\text { Esperta } \\
\text { Invejosa ou frustrada; } \\
\text { Baladeira; } \\
\text { Promíscua; } \\
\text { De esquerda; } \\
\text { De direita; } \\
\text { Interesseira/Oportunista; } \\
\text { Falsa/mau caráter/mentirosa; } \\
\text { Burra/ sem instrução / massa de } \\
\text { manobra; } \\
\text { Chata; } \\
\text { Terrorista/Criminosa da ditadura }\end{array}$ \\
\hline
\end{tabular}




\section{Resultados}

Organizamos a exposição dos resultados por sexo e depois em relação à concordância ou não com a linha editorial das revistas e as justificativas utilizadas. Em seguida, apresentamos os resultados em relação às três categorias acima. De modo geral, a distribuição dos comentários por sexo aponta que, em relação ao post da IstoÉ, os homens participaram mais vezes, correspondendo a $56,37 \%$ do total, enquanto as mulheres foram responsáveis por $43,31 \%$ dos comentários ${ }^{11}$. Em relação ao post com a reportagem da Veja, esse cenário se inverte: mulheres com 55,83\%, e homens com $43,46 \% 15^{12}$.

\section{Concordância}

A maior parte dos comentadores $(73,42 \%)$

da postagem da IstoÉ está de acordo com a postura editorial da revista em relação à presidenta Dilma (Figura 1). Desses, $56,47 \%$ eram homens e 43,53\% mulheres. Em 16,14\% dos comentários, encontramos discordância (Figura 1), e, neste caso, a distribuição entre homens e mulheres ficou equilibrada e correspondeu a $50 \%$ cada. Contudo, quando analisamos os motivos da discordância (Figura 2), 40\% dos comentários de mulheres apontam o machismo, seguido por "falta de credibilidade" (25,71\%) e "falta de seriedade" (20\%) da revista ${ }^{13}$, como é possível ver nos respectivos exemplos: "louca, descompensada entre outros adjetivos usados jamais seriam usados para um presidente, do sexo masculino" (B.A.D., 2 abr. 2016 ${ }^{14}$ ); "Não gosto [do] governo Dilma mas as notícias aqui vinculadas pela IstoÉ, não merecem credibilidade!" (L.C.G., 2 abr. 2016); "É sério isso? Parece matéria do Sensacionalista" (D.F.B, 2 abr. 2016).

A síntese das porcentagens de concordância e discordância pode ser vista no gráfico a seguir (Figura 1):

12 Não foi possível identificar sexo em $0,75 \%$ dos comentários.

13 Os outros percentuais são: 2,86\% discordam sem explicar e 11,43\% discorda por outros motivos.

14 Ao apresentarmos comentários como exemplos dos resultados encontrados, mantivemos a grafia original e, por isso, a maioria apresenta erros ortográficos ou uma linguagem própria da internet. Também optamos por colocar apenas as iniciais do comentador, seguidas pela data de postagem. 
Figura 1: Gráfico Concordância e Discordância por Revista (\%)

\section{Concordância e Discordância por Revista}

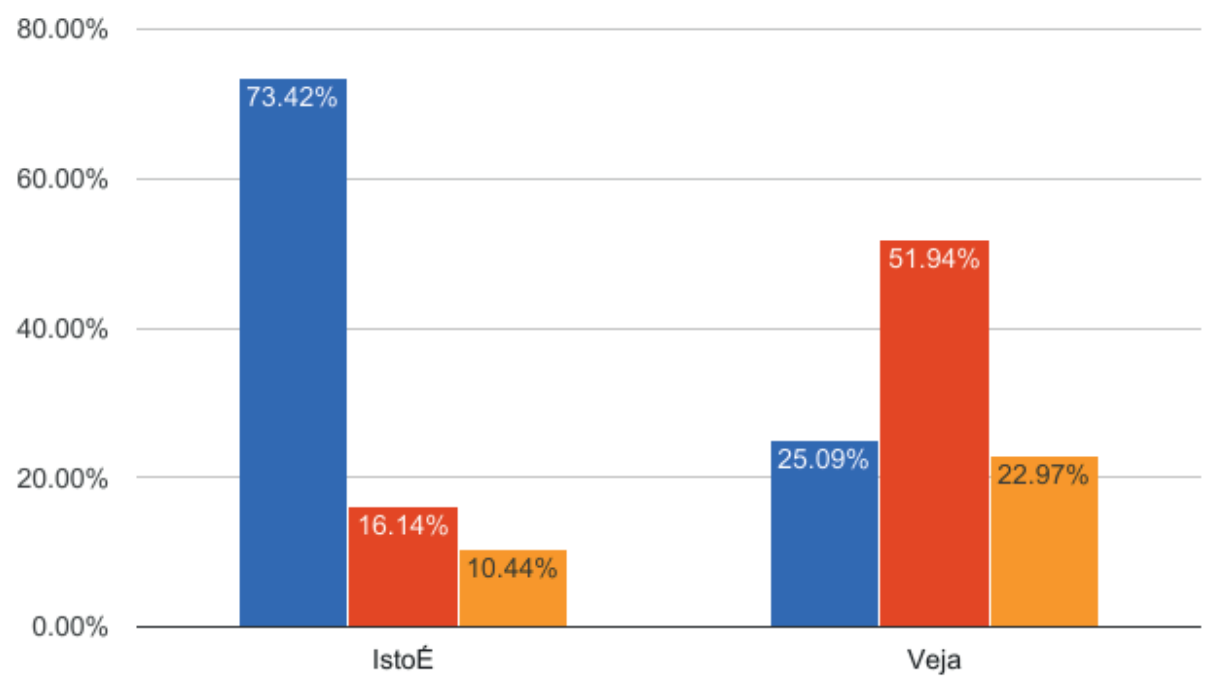

Fonte: Dados da pesquisa

Figura 2: Tipos de Discordância por Revista (\%)

\section{IstoÉ and Veja}

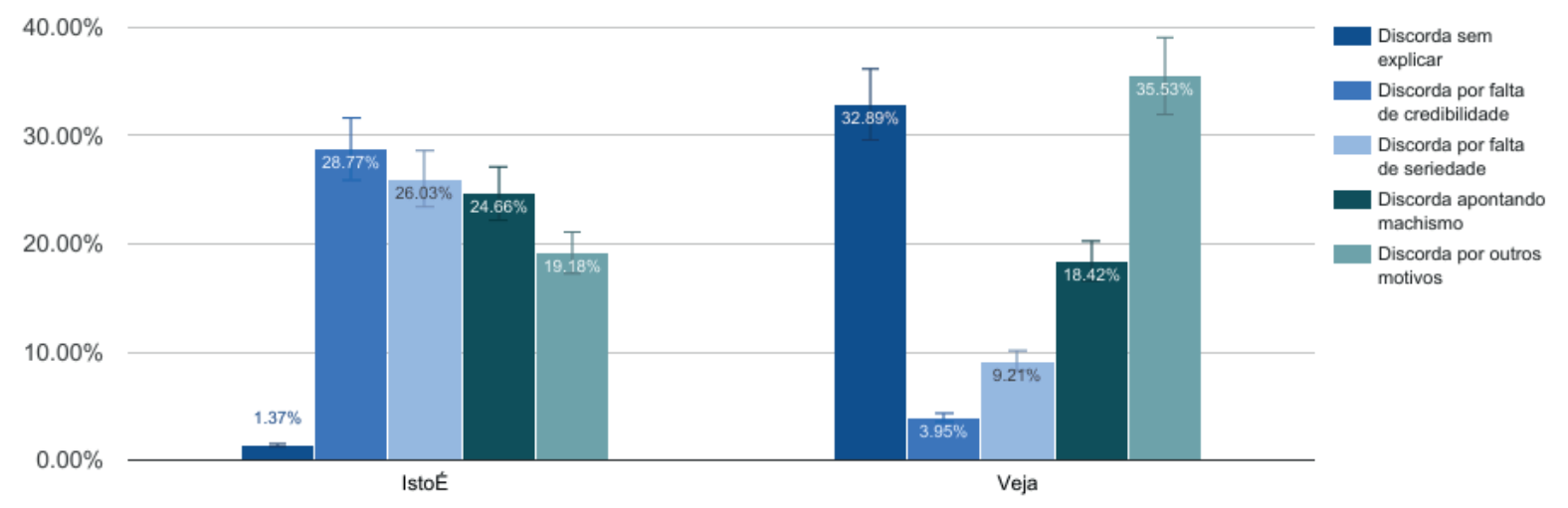

Fonte: Dados da pesquisa 
Os principais motivos de discordância (Figura

2) para os homens foram "falta de credibilidade" $(32,43 \%)$ e "falta de seriedade" (32,43\%), seguido por "outros motivos" (24,32\%), como desinteresse pela notícia, como no exemplo: "E pra quê eu quero saber disso? Contanto que ela pague o conserto de tudo, pode" (B.A. 1 abr. 2016).

Sobre a matéria da Veja "Bela, Recatada e do Lar", a maioria dos comentários apresentou discordância $(51,94 \%)$, outros $25,09 \%$ concordavam e, em 22,97\% não foi possível identificar (Figura 1). Dos que concordavam, $76 \%$ foram de homens e $24 \%$ de mulheres. Dentre os que discordavam da abordagem da revista, $68,03 \%$ foram de mulheres e $30,61 \%$ de homens ${ }^{15}$.

Quando discordavam, as mulheres, em geral, não explicavam o motivo (36,19\%), apontavam machismo (23,81\%) ou apresentavam outros motivos (Figura 2). Neste último caso, foram recorrentes comentários como: "Tantas mulheres boas, simples, lindas e recatadas existem no nosso Brasil! Estão longe dos holofotes! São esquecidas, sofridas e lutadoras!" (V.K., 18 abr. 2016) ou "É tão bom ter motivo de cancelar a assinatura das revistas da abril perderam um cliente pela matéria pobre, ridícula" (S.F., 20 abr. 2016).

Os homens, por sua vez não apresentavam justificativas para a discordância (22,22\%) ou apontavam outros motivos (60\%), neste caso geralmente, a depreciação do relacionamento com um homem mais velho ou interesse financeiro, como em "o objetivo eh esse. Qt mais velho for, mas chance tem de morrer logo e aí herdar toda a fortuna" (R.R. 19 abr. 2016).

\section{Atividade profissional}

Quanto às atividades profissionais, a maior parcela dos comentários do post da IstoÉ desvaloriza a mulher (56,83\%), enquanto apenas 4,13\% valorizam sua atuação em diferentes espaços profissionais. Em relação ao sexo dos autores dos comentários, principalmente mulheres valorizaram a atividade profissional de outras mulheres e destacaram a atuação política (61,54\% contra $38,46 \%$ de comentários masculinos).

Já os posicionamentos que desvalorizavam a atuação profissional da mulher foram sustentados em $63,69 \%$ dos casos por homens e em $36,31 \%$ por mulheres. 0 principal fator de desvalorização é a incompetência (50\% dos comentários de mulheres e $47,64 \%$ de homens), seguindo por "mulher corrupta" (33,64\% Mulher; 27,75\% Homem) e "atividade da política" (criticam o fato de a mulher ocupar cargo político ou se relacionar com política) (14,55\% Mulher; 20,94\% Homem).

São exemplos de comentários desses três últimos casos, respectivamente: "Mais um idiota defendendo esse governo incompetente" (F.L.C., 2 abr. 2016); 
"Então o que ela e os demais corruptos fazem não é desrespeito? Quantas pessoas morrem pelo interesse individual?" (A.G. 2 abr. 2016); "Mulher no comando de um pais é uma tragédia, Eu nunca mas votarei numa mulher para comandar algo" (R.B. 2 abr. 2016).

As respostas ao post da Veja sobre a reportagem com Marcela apontam um cenário relativamente distinto. A maioria não faz menção a atividades profissionais $(79,15 \%)$, outros $14,13 \%$ destacavam elementos de valorização da mulher e 6,36\% de desvalorização. A proporção de comentários entre homens e mulheres foi praticamente equivalente (valoriza: $42,4 \%$ Mulher, 57,5\% Homem; desvaloriza: 50\% cada). Ainda assim as justificativas apresentadas eram distintas. 0s homens ressaltaram positivamente de forma majoritária "atuando em casa e na família" (95,65\%). Para mulheres, os fatores de valorização foram distribuídos, principalmente, entre "atuando em casa com a família" $(36,84 \%)$ e "atuando onde deseja" (31,58\%).

No caso da Marcela Temer, as respostas que desvalorizam a mulher abordam como fatores a "atividade em casa" (30\%), relacionadas à prostituição e à atuação na política (ambas com $20 \%$ ) e a "mulher corrupta" (15\%). Exemplos desses casos são, respectivamente: "Dona de casa com um cartão de crédito ilimitado é fácil!" (R.0. 19 abr. 2016); "Qual a diferença entre uma mulher interesseira e uma prostituta? Se passa a ser uma figura pública julgamentos acabam acontecendo" (J.F. 19 abr. 2016); "Enfim, a beleza chega no Palácio do Planalto!!!" (L.C.R. 19 abr. 2016); "Só comendo as custas do dinheiro que foi roubado pelo marido" (P.Y. 18 abr. 2016).

\section{Temperamento}

Os comentários sobre o post da IstoÉ fizeram bastante referência a aspectos de temperamento. A maioria abordou termos que desvalorizam a mulher (57,59\%) e uma pequena porcentagem relacionou elementos de valorização $(2,53 \%)^{16}$. Entre todas as ocorrências de desvalorização, a mais citada foi "louca ou descontrolada" (63,33\%), seguida por "histérica" (17,78\%). Nesse item, houve pouca diferença entre comentários de mulheres e homens (47,25\% Mulher; 52,75\% Homem).

Em geral, quando os códigos "louca ou descontrolada" eram aplicados, encontramos comentários como "Não é de agora que Dilma mostra seu destempero, os discursos confusos e sem noção de realidade são veeeeeelhos" (J.M., 1 abr. 2016). Para 0 código "histérica", encontramos: "Em uma visita a Termomecânica [...], esta @\#\$\% (Senhora) obrigou aos gritos o motorista e seus seguranças a voltarem ao Hotel para buscar um casaco que havia esquecido" (E.M., 2 abril, 2016).

As referências positivas ocorreram pouco, com destaque para: "sensata" (33,33\% do total de 
ocorrências), "equilibrada" (25\%) e "mulher forte" (25\%). As mulheres foram as que fizeram mais comentários positivos (75\% Mulher; 25\% Homem), como por exemplo: "q matéria deplorável e pobre, admiro essa mulher por tudo que ela está passando e sofrendo, só desejo que ela possa passar essa fase e ficar em paz..." (E.F. 2 abr. 2016).

Nos comentários ao post de Veja, a ocorrência de referências a temperamento foi bem menor: 13,43\% que valorizavam a mulher, 4,95\% que desvalorizavam. $81,27 \%$ não abordaram temperamento e em 0,35\% não foi possível identificar.

Os homens foram os que mais fizeram referências positivas ao temperamento (65,79\% Homem; $34,21 \%$ Mulher). A categoria com maior destaque foi "comportada" (62,50\%), seguida por "simples" $(14,58 \%)$ e "forte" (10,42\%). Entre os homens, a característica mais apontada foi "comportada" (96\%) e, entre as mulheres, "simples" (30,43\%).
Como "comportada" temos o exemplo: "tá com inveja isso sim kkkkkkkkkkk, essa é recatada mesmo... paulista do interior, linda, decente....foi pedida em namoro aos pais" (J.C.J, 18 abr. 2016). Já a ideia de mulher "simples" está em "Sinceramente, eu 4.7 sem maquiagem, nunca fiz tratamentos de beleza, nem cirurgias plásticas, sou mamãe e avó de 4 lindos netos, solteirona, criei meu filho sozinha, construí minha casa simples [...]" (0.P., 18 abr. 2016).

Em relação aos posicionamentos que desvalorizam a mulher, a categoria mais recorrente foi "que se faz de vítima" (53,33\%), "exibida" (13,33\%) e "louca ou descontrolada" (13,33\%).

Para visualizar as categorias mais utilizadas pelos comentadores em relação ao temperamento, criamos uma nuvem de palavras capaz de revelar o nível de ocorrência (expresso no tamanho da palavra) e a correlação entre as palavras, conforme a Figura 3 (IstoÉ) e a Figura 4 (Veja):

Figura 3: Nuvem de palavras da categoria "Temperamento" nos comentários da revista IstoÉ

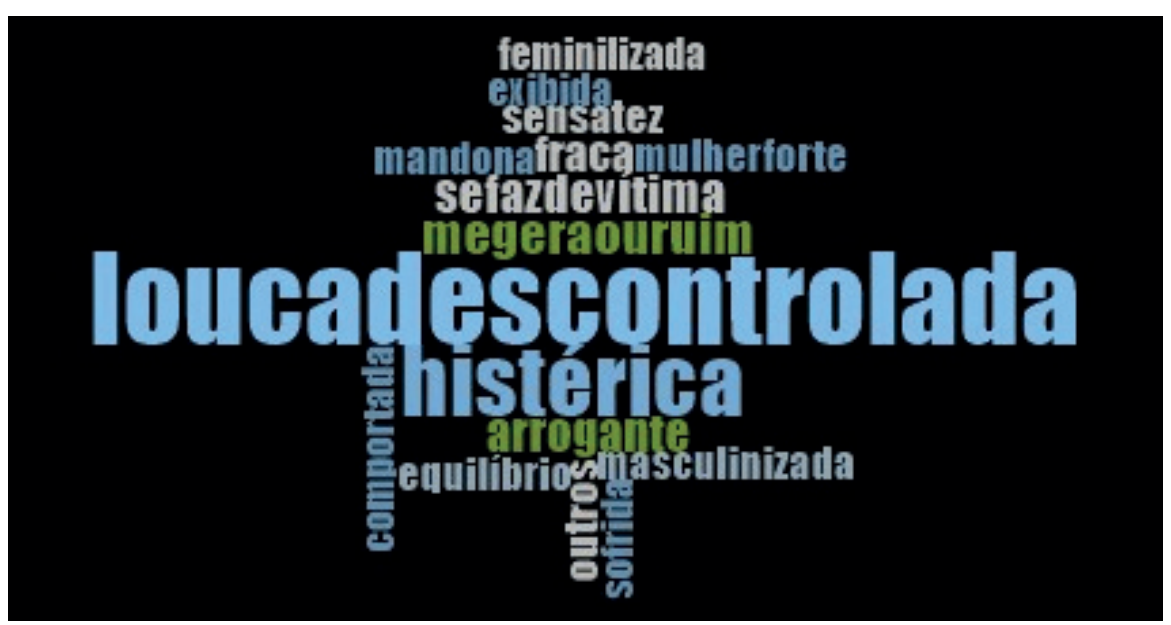


Figura 4: Nuvem de palavras da categoria "Temperamento" nos comentários da revista Veja

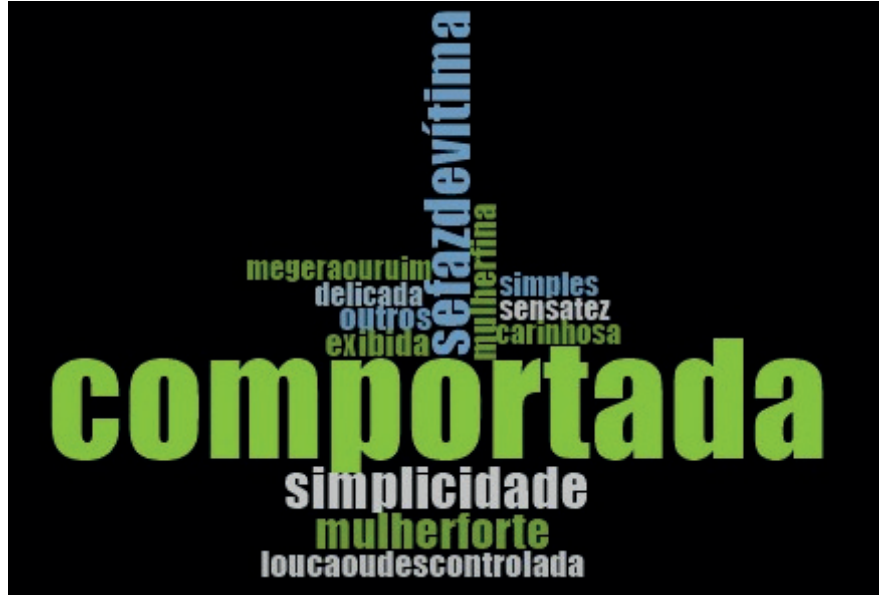

Fonte: Dados da pesquisa

\section{Relações sociais}

Na categoria "relações sociais", destacamos

os comentários que valorizam ou desvalorizam

o modo como a mulher se localiza ou age

socialmente. No post da IstoÉ, houve

predominância de comentários que desvalorizam

a mulher (37,46\%) em comparação com os

que valorizam (4,13\%). Entre os elementos

negativos, teve destaque "falsa ou mau-

caráter ou mentirosa" (49,13\%), seguido por

"burra" (18,50\%) e "de esquerda" (10,40\%). 0s

homens foram os que mais fizeram esse tipo de comentário (35,59\% Mulher; 63,56\% Homem).

Essas subcategorias podem ser ilustradas com as falas a seguir: "Pra Dilma e Lula, todo dia é dia da mentira" (M.M., 3 abr. 2016); "A jumenta sabe que a casa está caindo" (C.B., 1 abr. 2016); "A vadia comunista que ve defende mostrou a cara de guerrilheira psicopata e a culpa é de quem informa? Vai comer mortaNdela que vc ganha mais!" (S.R.C, 1 abr. 2016).

Entre os elementos de valorização, os mais recorrentes foram "empoderada" (16,67\%) e "decente" (16,67\%), como em "Dilma é uma mulher não um resto de homem frustrado" (J.P., 2 abr. 2016). Nessa categoria, as mulheres foram as que mais comentaram (53,85\% Mulher; 38,46\% Homem).

Sobre os comentários ao post de Veja, verificamos que $30,31 \%$ desvalorizam a mulher e $13,2 \%$ valorizam $^{17}$. Dos que desvalorizam, a maioria foi de homens (36,78\% Mulher; 62,07\% Homem). 0s elementos mais recorrentes nessa categoria foram: "interesseira ou oportunista" (51,02\%), por exemplo "0 que o dinheiro não faz..." (M.A.D, 20 abr. 2016), e "invejosa ou frustada" (16,33\%), 
como em "Mulheres falam mal de mulheres, isso é normal" (M.G. 18 abr. 2016).

Dos que desvalorizam, os homens também foram os principais comentaristas (39,48\% Mulher; $60,53 \%$ Homem) e as categorias mais valorizadas foram "obediente à família" (15,09\%) ("é uma família estruturada com filho, recatada, discreta e sensatos", F.L.D 18 abr. 2016), e "batalhadora" (13,21\%) ("dolar é quem acorda as 5 da manhã e pega cinco onibus e ganha salario minimo faz faxina em varias casas pra sobreviver enfrenta metro lotado tds os dias", G.Q. 19 abr. 2016).

\section{Análise: mapa de moralidades}

As redes sociais, especificamente 0 Facebook, no caso analisado, caracterizam-se como ambientes fundados na tensão entre público e privado, já que, ao mesmo tempo em que têm uma grande audiência em potencial (via redes de contato) e a possibilidade de manifestação relativamente autônoma dos indivíduos (PAPACHARISSI, 2010), configuram-se como espaços de interação cotidiana em que sujeitos se sentem, por vezes, numa posição confortável para emitir opiniões, 0 que pode contribuir para cristalizar preconceitos e rótulos ou desafiá-los.

A proposição do nosso mapa de moralidades a partir das conversações informais analisadas pode se dividir em três pontos: a) sentidos sedimentados historicamente pela hierarquia moral, b) sentidos desafiados e proposição de novas gramáticas morais e c) a articulação do sentido de injustiça como típico de um grupo.

Podemos considerar como elementos que constituem a moralidade da mulher em relação ao trabalho: a) 0 alto número de concordâncias com a matéria da revista IstoÉ (73,42\%), uma vez que a maioria de comentários desvaloriza a mulher na atividade profissional política $(56,83 \%)$; b) a supervalorização do trabalho em casa e na família nos comentários relacionados à postagem da Veja (72,5\% dentre aqueles que valoram positivamente); e c) a caracterização de incompetência na atuação política na IstoÉ (48,5\% dentre os que valoram negativamente).

A divisão sexual do trabalho expressa no nosso levantamento reforça o papel do cuidado do lar e da família como tarefa das mulheres (OKIN, 2008; CAL, 2016), ao passo que caracteriza negativamente a mulher na política. Marcela e Dilma parecem representar os polos dessa topografia moral que define a atividade laboral dentro de casa como de mais valor para a mulher. Está em questão o lugar da mulher na vida pública e no universo do trabalho, transcendendo as questões individuais de Dilma ou Marcela. Esses elementos morais que questionam o lugar das mulheres na vida pública representam um grande desafio para que as elas ocupem lugares de decisão e sejam reconhecidas como capazes e competentes nessa área. Como apontam Mota e Biroli (2016), a ausência de mulheres nessas esferas prejudica a 
transformação de suas experiências e interesses em pautas políticas consistentes.

As esferas do trabalho e da família são, segundo Taylor (1997), aquelas mais importantes na hierarquia social e moral que se configurou na modernidade. São as grandes definidoras daquilo que tem valor e se revelam em duas vertentes: a razão instrumental, cujo lugar privilegiado é a economia e o mundo do trabalho; e 0 expressivismo das subjetividades que tem no casamento baseado em sentimentos talvez sua objetificação mais importante. Essas duas esferas centrais para a configuração da moral moderna, trabalho e família, precisam assim dessa divisão sexual do trabalho para a sua manutenção. Essa divisão expressa-se nitidamente no material analisado.

Da mesma maneira, Taylor (1997) identifica em sua topografia moral das relações sociais que a racionalidade é uma importante virtude na modernidade, bem como a "resolução, determinação, controle e as virtudes do guerreiro" (SOUZA, 2000, p. 138). É valorizada na modernidade a noção de eficiência, poder, razão instrumental e neutralidade. "A 'boa vida nesse contexto é definida como controle racional e eficiente de si, dos outros e da natureza" (SOUZA, 2000, p. 138).

Historicamente, as mulheres são consideradas mais emotivas, enquanto os homens seriam mais racionais. Temperamentos considerados não racionais são vistos negativamente na vida pública - seara, por princípio, racional e procedimental. Nos comentários da IstoÉ, em 63,33\% dos comentários negativos, Dilma é chamada de louca ou descontrolada, e em 17,78\% de histérica. São características negativas tradicionalmente associadas à mulher e servem para desqualificar a sua atuação política, que não seria então desejavelmente racional. De modo distinto, nos comentários da Veja, "comportada" foi 0 adjetivo mais utilizado para caracterizar o temperamento de Marcela de maneira positiva, valorizando 0 lugar do privado concedido à mulher. Ser falsa, mau-caráter e burra foram características relacionadas às relações sociais estabelecidas por Dilma. Enquanto "decente" foi a principal referência às relações sociais estabelecidas por Marcela. Nota-se que os atributos da discrição e decência são valorizados e apreciados para uma mulher na vida pública. Quanto menos opiniões emitidas e expressões em público mais valor é atribuído a esse comportamento.

Conforme já discutido, muito da moralidade que ancora a imagem da mulher na vida pública é historicamente configurada por essa hierarquia que subjaz à divisão sexual do trabalho.

Entretanto, a partir de interações sociais e do desvendamento de determinadas questões, critérios valorativos podem ser questionados, desestabilizando determinadas moralidades e propondo novas gramáticas morais (HONNETH, 2003). Isso pode ser identificado nas críticas feitas às matérias da IstoÉ e da Veja. 
"Sensata", "equilibrada" e "mulher forte" são termos recorrentes utilizados para caracterizar Dilma e contrapor o posicionamento da revista. Ao mesmo tempo, 0 fato de Marcela dedicar-se ao lar é questionado e considerado negativo por $30 \%$ do universo dos comentários negativos. 0 próprio posicionamento de quem discorda da revista, cerca de $50 \%$, revela essas moralidades desafiadas a partir de novos sentidos sobre ser mulher na política ou na vida pública.

Por fim, consideramos, no nosso terceiro nível de análise, o fato de que: a) a maior parte dos que concordam com a abordagem da IstoÉ é composta por homens; b) dentre os que discordam tanto da Veja quanto da IstoÉ, apenas as mulheres consideram machistas as abordagens; c) a maior parte dos que concordam com a abordagem da Veja é formada por homens (76\%); d) a desvalorização da atuação da mulher na vida política é feita nas duas revistas, majoritariamente, por homens, enquanto as mulheres valorizam a possibilidade de escolha profissional das mulheres; e e) são as mulheres que, no geral, fazem mais comentários positivos em relação às duas matérias.

Isso significa que os processos de identificação de gênero, a partir da visibilidade e das experiências de Dilma e Marcela, levam as mulheres a compartilharem um vocabulário comum sobre sua condição, articulando essa condição a um "quadro de interpretações intersubjetivo que os comprova como típicos de um grupo inteiro" (HONNETH,
2003, p. 258). Essa semântica coletiva é essencial para 0 surgimento da identificação de questões de injustiça como típica da categoria das mulheres. Essas identificações entre mulheres passam a compor um horizonte de interpretação que dá sentido e motiva a luta de um grupo, além de arrancar outros que vivem os mesmos problemas da situação paralisante de injustiça. Revela também que a percepção do machismo entre homens e mulheres é bastante diferente, visto que a experiência cotidiana de ser mulher pode conduzir a uma identificação mais recorrente de casos de machismo, misoginia, oportunidades iguais ou direito de escolha.

\section{Considerações finais}

0 mapa de moralidades é construído por meio do que chamamos de padrões, compostos por um agrupamento de significantes e suas respectivas semânticas. Ainda que espaços de visibilidade, em princípio, abertos ao debate, como as redes sociais online, apresentem o potencial para questionar modos conservadores de compreender a atuação das mulheres na política,o mapa de moralidades apresentado indica que houve nos casos analisados, principalmente, um reforço a modos de percepção da relação entre mulheres e política baseados, sobretudo, na divisão sexual tradicional do trabalho.

Posicionamentos intolerantes ou conservadores ganham a arena pública por meio dos media exatamente porque fazem parte da vida social de 
forma latente e são mobilizados nas discussões que os sujeitos travam nas redes sociais.

Entretanto, a pesquisa que empreendemos desenha esse quadro da cristalização de valores e de um pano de fundo moral conservador a respeito da participação de mulheres na vida pública, mas também aponta fatores que desafiam esses padrões e vislumbram a articulação do sentido de injustiça como típico de um grupo - as mulheres, no nosso caso. Outro achado importante deste estudo refere-se aos valores/posicionamentos acionados de modo distinto por homens e por mulheres, o que nos ajuda a compreender a tessitura social desse pano desse fundo moral e, com isso, estabelecer elementos consistentes para questioná-lo.

\section{Referências}

ARENDT, Hannah. A Condição Humana [1958]. Rio de Janeiro, Forense Universitária, 1992, p.15-90.

BARDIN, Laurence. Análise de conteúdo. Lisboa: Edições 70, 1995.

BIR0LI, Flávia. 0 público e o privado. In: MIGUEL, L.F.; BIROLI, F. Feminismo e Política: uma introdução. São Paulo: Boitempo, 2014, p. 31-46.

BUTLER, Judith. Merely Cultural. NLR, I/227, Jan./Feb. 1998.

Problemas de gênero: feminismo e subversão da identidade. Tradução de Renato Aguiar. Rio de Janeiro: Editora Civilização Brasileira, 2003.

CAL, Danila Gentil Rodriguez. Comunicação e trabalho infantil doméstico: política, poder, resistências. Edufba; Brasília, Compós, 2016. COHEN, Jacob. A coefficient of agreement for normal scales. Educational and Psychological Measurement, v. 20, n.1, 1960.

FRANÇA, Vera. Sujeitos da Comunicação, sujeitos em comunicação. In: FRANÇA, V.R.V.; GUIMARÃES, C.. (Org.). Na mídia, na rua: narrativas do cotidiano. $1^{\mathrm{a}}$ ed. Belo Horizonte: Autêntica, 2006.

GARCÊZ, Regiane L. 0.; CAL, Danila Gentil Rodriguez. Deslizes morais na cena midiática: reprodução da intolerância ou oportunidade para novas gramáticas morais? E-Compós (Brasília), v. 16, p. 1-17, 2013.

GOMES, Wilson. Da discussão à visibilidade. In: GOMES, W.; MAIA, R. Comunicação e Democracia: problemas e perspectivas. Paulus: São Paulo, 2008.

HABERMAS, Jürgen. Communication and the

Evolution of Society. Boston, MA: Beacon Press, 1979. Mudança Estrutural da Esfera Pública. Rio de Janeiro: Tempo Brasileiro, 2003. Communication and the Evolution of Society. Boston: Beacon Press, 1979.

HONNETH, Axel. Luta por reconhecimento. A gramática moral dos conflitos sociais. Trad. Luiz Repa. São Paulo: Ed. 34, 2003.

KOFES, Suely. Categorias analítica e empírica: gênero e mulher: disjunções, conjunções e mediações. Cadernos Pagu, n. 1, p. 19-30, 1993.

KOLBE, Richard. H.; BURNETT, Melissa. S. Content analysis research: an examination of applications with directives for improving research reliability and objectivity. Journal of Consumer Research, 18(2), 243-250, 1991.

LINHARES, Juliana. Bela, recatada e "do lar". Revista Veja, 18 abr. 2016. Disponível em http://veja.abril.com. br/brasil/marcela-temer-bela-recatada-e-do-lar/. Acesso em> 03 mar. 2017.

MCNAY, Lois. Against Recognition. Cambridge, UK, Malden, MA: Polity Press, 2008. 
MAIA, Rousiley. C. M. Deliberation, the media and political talk.New York, NY: Hampton Press, 2012.

Mídia e deliberação. Rio de Janeiro, RJ:

Editora FGV, 2008.

Recognition and the Media. led.Hampshire:

Palgrave Macmillan, 2014.

MARKELL, Patchen. Bound by Recognition.

Princeton: Princeton University Press, 2003.

MATOS, Marlise. Teorias de gênero ou teorias e

gênero? Se e como os estudos de gênero e feministas

se transformaram em um campo novo para as ciências.

Rev. Estud. Fem., Florianópolis , v. 16, n. 2, p. 333-357, 2008.

MENDONÇA, Ricardo. F. Reconhecimento em debate: os modelos de Honneth e Fraser em sua relação com 0 legado Habermasiano. Rev. Sociol. Polit., Curitiba, $n$. 29, p. 169-185, Nov. 2007.

MIGUEL, Luís. F. A identidade e a diferença. In: MIGUEL, L.F.; BIROLI, F. Feminismo e Política: uma introdução. São Paulo: Boitempo, 2014.

MOTA, Fernanda Ferreira; BIR0LI, Flávia. 0 gênero na política: a construção do "feminino" nas eleições presidenciais de 2010. Cadernos Pagu, n. 43, p. 197$231,2016$.

MOUFFE, Chantal. Feminism, Citizenship, and Radical Democratic Politics. In: BUTLER, J.; SCOTT, J. Feminists Theorize the Political. London: Routledge, 1992.

OKIN, Susan Moller. Gênero, o público e o privado.

Estudos Feministas, Florianópolis, v.16, n 2, p. 305332, mai/ago. 2008.

PAPACHARISSI, Zizi. A private sphere: democracy in a digital age. Cambridge: Polity, 2010.

PARDELLAS; Sérgio.; BERGAMASC0, Débora. Uma presidente fora de si. Revista IstoÉ, $\mathrm{n}^{0}$ 2417, 06 abr 2016. Disponível em http://istoe.com.br/450027_
UMA+PRESIDENTE + FORA+DE + SI/. Acesso em 03 mar. 2017.

SARDENBERG, Cecília. Back to women? Translations, resignifications and myths of gender in policy and practice in Brazil. In: CRONWELL, A.; HARISSON, E.; WHITEHEAD, A. (eds) Feminisms in development: Contradictions, contestations and challenges. London: Zed Books, 2007.

SOUZA, Jessé. Charles Taylor e a teoria crítica do reconhecimento. In: SOUZA, Jessé. A modernização seletiva: uma reinterpretação do dilema brasileiro. Brasília: UnB, 2000.

TAYLOR, Charles. Argumentos Filosóficos. Loyola, 1995.

As fontes do self. São Paulo: Loyola, 1997.

TSE. Estatísticas Eleitorais 2016 - Eleitorado. Disponível em http://www.tse.jus.br/eleicoes/ estatisticas/estatisticas-eleitorais-2016/eleicoes-2016. Acesso em 10 nov.2016.

VELOSO, Ana Maria Conceição; VASCONCELOS, Fabíola Mendonça de; FERREIRA, Laís. As duas faces do sexismo na mídia: como Marcela Temer e Dilma Rousseff (PT) são retratadas pela Veja e IstoÉ. Revista Observatório, [S.l.], v. 3, n. 1, p. 58-83, mar. 2017.

WARREN, Mark. What should and should not be said: Deliberating Sensitive Issues. Journal of Social Philosophy, v.37, n. 2, p.163-181, 2006. 


\begin{tabular}{|c|c|}
\hline $\begin{array}{l}\text { Woman in public life: a map } \\
\text { of moralities on Facebook }\end{array}$ & $\begin{array}{l}\text { La mujer en la vida pública: un mapa } \\
\text { de las moralidades en Facebook }\end{array}$ \\
\hline $\begin{array}{l}\text { Abstract } \\
\text { The article investigates moral agreements about the } \\
\text { woman's presence in the public life, taking as corpus } \\
\text { some Facebook posts sharing the news: The nervous } \\
\text { explosions of the president, originally printed on } \\
\text { IstoÉ, a Brazilian magazine, and Beautiful, chaste } \\
\text { and housewife, from Veja. We draw a map of the } \\
\text { moralities concerning the professional activities, } \\
\text { temper and social relation, which points out as tacit } \\
\text { consensuses: a positive eye on the image of the } \\
\text { discreet woman that acts as a nice housewife and, on } \\
\text { the other hand, a negative view on the women who } \\
\text { submit themselves to their emotions. To defy these } \\
\text { conceptions, there's the idea of the strong woman } \\
\text { who can chose her professional life. We observed } \\
\text { that the moralities reputed as offensive are able to } \\
\text { create some identification and find affinities in order } \\
\text { to establish new moral grammars. } \\
\text { Keywords } \\
\text { Woman. Moralities. Facebook }\end{array}$ & $\begin{array}{l}\text { Resumen } \\
\text { El artículo investiga las avenencias morales respeto } \\
\text { a la participación de la mujer en la vida pública } \\
\text { partiendo de los comentarios en posts de Facebook } \\
\text { con las noticias Las explosiones nerviosas de la } \\
\text { presidente, publicada en IstoÉ, y Bella, resguardada } \\
\text { y del hogar, de Veja. En un mapa de las moralidades } \\
\text { sobre actividades profesionales, temperamentos y } \\
\text { relaciones sociales se señalaron como consensos } \\
\text { tácitos: la visión positiva de la mujer discreta y } \\
\text { responsable por el hogar y, por otra parte, la visión } \\
\text { negativa de la mujer que se rinde a sus emociones. } \\
\text { Desafían esas concepciones: la idea de mujer fuerte } \\
\text { y que puede elegir la vida profesional, identificamos } \\
\text { que moralidades consideradas ofensivas pueden } \\
\text { crear identificación y afinidades que apuntan para la } \\
\text { instauración de nuevas gramáticas morales. } \\
\text { Palabras-clave } \\
\text { Mujer. Moralidades. Facebook. }\end{array}$ \\
\hline
\end{tabular}

Woman. Moralities. Facebook 


\section{Expediente}

A revista E-Compós é a publicação científica em formato eletrônico da Associação Nacional dos Programas de Pós-Graduação em Comunicação (Compós). Lançada em 2004, tem como principal finalidade difundir a produção acadêmica de pesquisadores da área de Comunicação, inseridos em instituições do Brasil e do exterior.

\section{E-COMPÓS I www.e-compos.org.br I E-ISSN 1808-2599}

Revista da Associação Nacional dos Programas de Pós-Graduação em Comunicação. Brasília, v.21, n.1, jan./abr. 2018. A identificação das edições, a partir de 2008 , passa a ser volume anual com três números. Indexada por Latindex I www.latindex.unam.mx

\section{CONSELHO EDITORIAL}

Ada Cristina Machado Silveira, Universidade Federal de Santa Maria, Brasil Alda Cristina Silva da Costa, Universidade Federal do Pará, Brasil Alfredo Luiz Paes de Oliveira Suppia, Universidade Estadual de Campinas, Brasil Ana Regina Barros Rego Leal, Universidade Federal do Piauí, Brasil Ana Carolina Rocha Pessôa Temer, Universidade Federal de Goiás, Brasil André Luiz Martins Lemos, Universidade Federal da Bahia, Brasil Angela Cristina Salgueiro Marques, Universidade Federal de Minas Gerais, Brasil Ângela Freire Prysthon, Universidade Federal de Pernambuco, Brasil Antonio Carlos Hohlfeldt, Pontifícia Universidade Católica do Rio Grande do Sul, Brasil Arthur Ituassu, Pontifícia Universidade Católica do Rio de Janeiro, Brasil

Bruno Campanella, Universidade Federal Fluminense, Brasil

Cláudio Novaes Pinto Coelho, Faculdade Cásper Líbero, Brasil Cárlida Emerim, Universidade Federal de Santa Catarina, Brasil Carlos Eduardo Franciscato, Universidade Federal de Sergipe, Brasil Danilo Rothberg, Universidade Estadual Paulista, Brasil Denise Tavares da Silva, Universidade Federal Fluminense, Brasil Diógenes Lycarião, Universidade Federal do Ceará, Brasil Eduardo Vicente, Universidade de São Paulo, Brasil Eliza Bachega Casadei, Escola Superior de Propaganda e Marketing - SP, Brasil Eneus Trindade, Universidade de São Paulo, Brasil

Erick Felinto de Oliveira, Universidade do Estado do Rio de Janeiro, Brasil Erly Vieira Júnior, Universidade Federal do Espírito Santo, Brasil Francisco de Assis, FIAM-FAAM Centro Universitário, Brasi

Francisco Elinaldo Teixeira, Universidade Estadual de Campinas, Brasi Francisco Gilson R. Pôrto Jr., Universidade Federal do Tocantins, Brasil Frederico de Mello Brandão Tavares, Universidade Federal de Ouro Preto, Brasil Gabriela Reinaldo, Universidade Federal do Ceará, Brasil Gilson Vieira Monteiro, Universidade Federal do Amazonas, Brasil Gustavo Daudt Fischer, Universidade do Vale do Rio dos Sinos, Brasi Itania Maria Mota Gomes, Universidade Federal da Bahia, Brasil Jiani Adriana Bonin, Universidade do Vale do Rio dos Sinos, Brasil José Afonso da Silva Junior, Universidade Federal de Pernambuco, Brasil José Luiz Aidar Prado, Pontifícia Universidade Católica de São Paulo, Brasil Josette Maria Monzani, Universidade Federal de São Carlos, Brasi Juçara Gorski Brittes, Universidade Federal de Ouro Preto, Brasil
Juliana Freire Gutmann, Universidade Federal da Bahia, Brasil Laura Loguercio Cánepa, Universidade Anhembi Morumbi, Brasil Leonel Azevedo de Aguiar, Pontifícia Universidade Católica do Rio de Janeiro, Brasil Letícia Cantarela Matheus, Universidade do Estado do Rio de Janeiro, Brasil Luciana Coutinho Souza, Universidade de Sorocaba, Brasil Maria Ataide Malcher, Universidade Federal do Pará, Brasil Maria Elisabete Antonioli, Escola Superior de Propaganda e Marketing - SP, Brasil Maria das Graças Pinto Coelho, Universidade Federal do Rio Grande do Norte, Brasil Marialva Carlos Barbosa, Universidade Federal do Rio de Janeiro, Brasil Marcel Vieira Barreto Silva, Universidade Federal da Paraíba, Brasil Marcia Tondato, Escola Superior de Propaganda e Marketing, Brasil Marli Santos, Universidade Metodista de São Paulo, Brasil

Márcio Souza Gonçalves, Universidade do Estado do Rio de Janeiro, Brasil Mauricio Mario Monteiro, Universidade Anhembi Morumbi, Brasil Mayka Castellano, Universidade Federal Fluminense, Brasil

Mozahir Salomão Bruck, Pontifícia Universidade Católica de Minas Gerais, Brasil Nisia Martins Rosario, Universidade Federal do Rio Grande do Sul, Brasil Paolo Demuru, Universidade Paulista, Brasil

Paula Melani Rocha, Universidade Estadual de Ponta Grossa, Brasil Potiguara Mendes Silveira Jr, Universidade Federal de Juiz de Fora, Brasil Priscila Ferreira Perazzo, Universidade Municipal de São Caetano do Sul, Brasil Rafael Cardoso Sampaio, Universidade Federal do Paraná, Brasil Rafael Tassi Teixeira, Universidade Tuiuti do Paraná, Brasil Regiane Lucas Garcês, Universidade Federal de Minas Gerais, Brasil Regiane Regina Ribeiro, Universidade Federal do Paraná, Brasil Renata Pitombo Cidreira, Universidade Federal do Recôncavo da Bahia, Brasil Renato Essenfelder, Escola Superior de Propaganda e Marketing, Brasil Roberto Elísio dos Santos, Universidade Municipal de São Caetano do Sul, Brasil Rodolfo Rorato Londero, Universidade Estadual de Londrina, Brasil Roseli Figaro, Universidade de São Paulo, Brasil

Simone Maria Andrade Pereira de Sá, Universidade Federal Fluminense, Brasil Sofia Cavalcanti Zanforlin, Universidade Católica de Brasília, Brasil Sônia Caldas Pessoa, Universidade Federal de Minas Gerais, Brasil Tatiana Oliveira Siciliano, Pontifícia Universidade Católica do Rio de Janeiro, Brasil Thaïs de Mendonça Jorge, Universidade de Brasília, Brasil

Valquiria Michela John, Universidade Federal do Paraná, Brasil

\section{CONSELHO CIENTÍFICO}

Cristiane Freitas Gutfreind, Pontifícia Universidade Católica do Rio Grande do Sul, Brasil | Eduardo Antônio de Jesus, Universidade Federal de Minhas Gerais, Brasil I Eduardo Morettin, Universidade de São Paulo, Brasil I Irene de Araújo Machado, Universidade de São Paulo, Brasil I Miriam de Souza Rossini, Universidade Federal do Rio Grande do Sul, Brasil

\section{COMISSÃO EDITORIAL}

Igor Pinto Sacramento, Universidade Federal do Rio de Janeiro, Brasil I Kelly Cristina de Souza Prudencio, Universidade Federal do Paraná, Brasil I Osmar Gonçalves dos Reis Filho, Universidade Federal do Ceará, Brasil I Rafael Grohmann, Faculdade Cásper Líbero, Brasil I Thaiane Moreira de Oliveira, Universidade Federal Fluminense, Brasil (editores associados)

\section{CONSULTORES AD HOC}

Afonso de Albuquerque, Universidade Federal Fluminense, Brasil I Cláudia Lago, Universidade de São Paulo, Brasil I Cesar Baio Santos, Universidade Federal do Ceará, Brasil I Eduardo Pellanda, Pontifícia Universidade Católica do Rio Grande do Sul, Brasi | Francisco Rüdiger, Pontifícia Universidade Católica do Rio Grande do Sul, Brasil | Karina Woitowicz, Universidade Estadual de Ponta Grossa, Brasil I Luis Mauro Sa Martino, Faculdade Cásper Líbero, Brasil I Norval Baitello Jr, Pontifícia Universidade Católica de São Paulo, Brasil I Pedro Guimarães, Universidade de Campinas, Brasil

\section{EQUIPE TÉCNICA}

ASSISTENTES EDITORIAIS Márcio Zanetti Negrini e Melina Santos । REVISÃO DE TEXTOS Fátima Áli | EDITORAÇ̃̃O ELETRÔNICA Roka Estúdio
COMPÓS I www.compos.org.br

Associação Nacional dos Programas de Pós-Graduação em Comunicação

Presidente

Marco Roxo

Programa de Pós-Graduação em Comunicação - UFF marcos-roxo@uol.com.br

Vice-Presidente

Isaltina Gomes

Programa de Pós-Graduação em Comunicação - UFPE

isaltina@gmail.com

Secretária-Geral

Gisela Castro

Programa de Pós-Graduação em Comunicação

e Práticas de Consumo - ESPM

castro.gisela@gmail.com

CONTATO I revistaecompos@gmail.com 